\title{
El riesgo de inundaciones y la vulnerabilidad en áreas urbanas. Análisis de casos en España
}

\author{
Flood risks and urban vulnerability: \\ some Spanish case studies
}

\author{
Mercedes Arranz Lozano*
}

\section{INTRODUCCIÓN}

En 1989 los geógrafos Cutter y Solecki, propusieron un modelo de "peligros de lugar", con el fin de analizar las consecuencias que los riesgos naturales causaban a una escala local de ciudad, barrio u otro sector concreto. Las consecuencias de dichos peligros se podían definir, según dichos autores, como la combinación de estructuras políticas y sociales que originaban lugares y gente vulnerables dentro de los mismos. De tal manera que a esa escala local, la vulnerabilidad social se convertía en una función de indicadores demográficos (género, economía, educación, etc.), o de movilidad/transporte o de percepción del riesgo. Con ello se obtendría una interacción de los peligros del lugar (riesgo y mitigación) con el perfil social de las comunidades, el cual proporcionaría un indicador global de la vulnerabilidad de los lugares (Cutter, S. L., 1993).

Siguiendo esta misma premisa en este trabajo, se desea abordar las consecuencias negativas que causan las inundaciones en áreas urbanas en España, a escala local, donde se han elegido cuatro casos en los que las inundaciones, originadas por diferentes episodios de lluvias torrenciales, dejaron grandes daños. Con ello se pretende analizar por qué se convirtieron en espacios tan vulnerables ante este riesgo, a pesar de ocurrir en un

* Universidad de La Laguna: marranz@ull.es 
país que es conocido por los grandes perjuicios que han dejado las inundaciones a lo largo del tiempo y en el que además existen medidas de respuestas propias de una nación desarrollada.

En este trabajo se pretende demostrar las siguientes hipótesis:

- La vulnerabilidad de algunos espacios urbanos concretos se ha incrementado, en las últimas décadas, como resultado del crecimiento espontáneo, no regulado que va surgiendo en sus periferias. Ello hace que la construcción se vaya realizando en áreas próximas a los cauces de los ríos y barrancos que, ante la presencia de lluvias intensas, aumentan enormemente sus caudales y al encontrar obstruidas las salidas naturales, causan daños irreversibles sobre la población allí asentada.

- A escala local, en muchos sectores urbanos, se construyen infraestructuras de drenaje que son insuficientes para encauzar la gran cantidad de agua que cae cuando se presentan determinados episodios de lluvias torrenciales. Si a ello se suma la existencia de grandes densidades urbanísticas en dichas áreas, nos encontramos con que, ellas mismas, constituyen obstáculos que obstruyen la salida natural de las aguas de lluvia.

- En espacios turísticos la vulnerabilidad puede llegar a incrementarse, debido a que diversos organismos públicos desean potenciar excesivamente medidas de desarrollo local. Este hecho obedece a depositar en exceso un elevado grado de confianza en la técnica y a olvidar los daños que en el pasado dejaron, en los mismos lugares, algunos episodios de Iluvias torrenciales de gran intensidad, si bien es verdad que parece aumentar la frecuencia con la que se están repitiendo dichos episodios, en los últimos años, como consecuencia del cambio climático.

Para llevar a cabo este trabajo se ha contado con diferentes fuentes de datos. Para los apartados sobre víctimas mortales originadas por Riesgos Naturales, se ha utilizado la base de datos que viene elaborando, desde 1990, la Dirección General de Protección Civil y Emergencias. En dicha base de datos se ha encontrado además del tipo de riesgo que produjo la víctima, información sobre la fecha, el lugar y la causa que determinó el óbito, con lo cual se tiene una información muy completa sobre las causas que originaron los fallecidos por riesgos naturales. Toda esta información está recogida, en los Anuarios que publica el Ministerio del Interior'.

1. También es la misma fuente que ha utilizado el Ministerio de Medio Ambiente para realizar la publicación: Perfil ambiental de España. Informe basado en indicadores, editado durante 2004 y 2005. 
Por lo que se refiere a la información que se adjunta sobre datos económicos, ésta se ha podido obtener consultando una importante base documental referida a las subvenciones e indemnizaciones económicas que aprueba el Gobierno mediante Órdenes, Reales Decreto-Ley y Leyes y tienen como objeto auxiliar a la población que, desgraciadamente, ha sufrido una catástrofe originada por un riesgo. Algunas de esas ayudas económicas son gestionadas y materializadas por el Ministerio del Interior a través de Dirección General de Protección Civil y Emergencias². En este sentido se han podido observar algunos problemas, como es que las cantidades abonadas por esta Dirección a la población, se refieren al conjunto de dinero que se ha pagado en un año por todos los daños sufridos, por distintos riesgos ocurridos en ese año, en distintas provincias españolas; pero no existe una desagregación clara de lo aportado en función del tipo de riesgo que ha producido los daños. A este respecto cabe señalar que lluvias intensas-inundaciones, asociados con vientos fuertes o desprendimientos de terrenos, es el tipo de riesgo por el que más dinero se ha pagado durante todo el periodo de tiempo estudiado. Junto a las inundaciones se abonaron, asimismo, importantes cantidades para sufragar daños ocasionados por el terremoto de Mula (Murcia) y por el desprendimiento de laderas ocasionado por la falla de Benamejí (Córdoba).

Para el análisis de los casos concretos de inundaciones expuestos en este trabajo, se han utilizado como fuentes de investigación, la documentación aportada por la Dirección General de Protección Civil, así como las obtenidas por diversos medios de comunicación y textos jurídicos existentes, para el caso de Biescas.

\section{LA IMPORTANCIA DE LOS DAÑOS QUE CAUSAN LAS INUNDACIONES EN ESPAÑA}

La importancia del daño que han causado las inundaciones en España, ha sido puesto de manifiesto, en varias ocasiones, por diversos autores (Ayala-Carcedo, F. J., 2002; Ayala-Carcedo, F. J., Olcina, J. y Vilaplana, J. M., 2004; Ayala-Carcedo, F. J. y Olcina, J., 2002). No obstante, con este trabajo que ahora se expone se desea contribuir, una vez más, a valorar las consecuencias que este peligroso riesgo ha seguido provocando en los últimos dieciséis años y por qué se siguen repitiendo.

2. Existen otras fuentes de consulta sobre pérdidas económicas y subvenciones como son las que otorga, principalmente por inundaciones, el Consorcio de Compensación de Seguros y de Agroseguro, que han sido utilizadas en publicaciones anteriores. 


\section{Las pérdidas en vidas humanas}

De todos los riesgos naturales analizados durante el periodo que se extiende desde 1990 a 2005, el que mayor número de víctimas mortales ha causado sobre la población en España ha sido el de inundaciones, que ha supuesto el $31,4 \%$ del total de fallecidos ${ }^{3}$. Porcentaje que se eleva a casi un $40 \%$ del total si le sumamos los ocasionados por deslizamientos de terrenos ${ }^{4}$. A este elevada cifra de fallecidos por inundaciones, le seguiría, a una larga distancia la ocasionada por vientos fuertes ${ }^{5}$, que representa, aproximadamente, la mitad de aquella. A su vez, al número de fallecidos ocasionados por estos dos riesgos le seguiría en importancia, el ocasionado por los incendios forestales (véase cuadro 1).

Analizando las víctimas mortales originadas por inundaciones, se observa que las mayores cifras se extiende desde 1994 hasta 1997, alcanzándose el mayor valor en el año 1996, con ciento diez fallecidos, que representó el $81,5 \%$ del total de las víctimas mortales registradas en ese año; le sigue el año 1997, cuando la cifra se elevó a cuarenta fallecidos, representando también el $61,5 \%$ del total de aquel año. A estos dos años fatídicos en número de víctimas mortales, le siguió un tercero 1995, con una cifra que ascendió a veintidós, lo que representó el 35,0\% del total en dicho año (véanse cuadro 1 y figura 1).

Así pues, estos tres años consecutivos estuvieron marcados por la desgracia y la catástrofe originadas por tres episodios de lluvias torrenciales, cuyas responsables fueron la presencia de sendas depresiones aisladas en altura (DANA), que originaron grandes inundaciones. El peor de los todos fue el episodio que sucedió el día 7 de agosto de 1996, en Biescas, el cual causó la muerte, en una sola riada, a ochenta y siete personas. Ésta fue la razón por la que, en dicho año, la cifra total de fallecidos por inundaciones se elevó a ciento diez, siendo además, 1996, el que presentó

3. Los profesores Ayala, J. F, Olcina, J. y Vilaplana, J. M. (2004), habiendo utilizado otras fuentes de datos, obtuvieron resultados distintos sobre el número de víctimas mortales por inundaciones (consúltese bibliografía).

4. En España los fallecidos por el riesgo de deslizamientos de terrenos, la mayoría de las veces, obedecen a la presencia de episodios de lluvias intensas que han caído con anterioridad a que se produzca el deslizamiento de terreno y éstos ocurren porque las lluvias o bien han removido el terreno o lo han dejado muy blando, hasta el punto de poder derrumbarse y ocasionar víctimas mortales; por esta razón es importante sumar éstas a las ocasionadas por la acción directa de las inundaciones.

5. En donde se incluyen las personas que fueron alcanzadas por un golpe de mar en la costa. 
mayor número de víctimas mortales, superior incluso al promedio todo el periodo de tiempo estudiado (dieciséis) (véanse cuadro 1 y figura 1).

Cuadro 1. Fallecidos por Riesgos naturales en España 1990-2005

\begin{tabular}{|c|c|c|c|c|c|c|c|c|c|}
\hline Años & $\begin{array}{l}\text { Inunda- } \\
\text { ciones }\end{array}$ & $\begin{array}{l}\text { Desliza. } \\
\text { terrenos }\end{array}$ & $\begin{array}{l}\text { Incendios } \\
\text { forestales }\end{array}$ & $\begin{array}{c}\text { Aludes } \\
\text { de nieve }\end{array}$ & $\begin{array}{c}\text { Episodios } \\
\text { de nieve } \\
\text { y frío }\end{array}$ & Tormentas & $\begin{array}{l}\text { Vientos } \\
\text { fuertes }\end{array}$ & $\begin{array}{c}\text { Olas de } \\
\text { calor }\end{array}$ & Total \\
\hline 1990 & 9 & 2 & 4 & 4 & 3 & 10 & 8 & 0 & 40 \\
\hline 1991 & 7 & 3 & 6 & 20 & 0 & 15 & 4 & 0 & 55 \\
\hline 1992 & 3 & 4 & 15 & 5 & 1 & 10 & 1 & 0 & 39 \\
\hline 1993 & 3 & 11 & 9 & 3 & 4 & 8 & 1 & 0 & 39 \\
\hline 1994 & 12 & 1 & 28 & 4 & 5 & 3 & 26 & 0 & 79 \\
\hline 1995 & 22 & 7 & 8 & 7 & 0 & 11 & 8 & 0 & 63 \\
\hline 1996 & 110 & 8 & 1 & 1 & 2 & 3 & 10 & 0 & 135 \\
\hline 1997 & 40 & 2 & 4 & 0 & 5 & 7 & 7 & 0 & 65 \\
\hline 1998 & 0 & 0 & 4 & 0 & 1 & 1 & 1 & 0 & 7 \\
\hline 1999 & 5 & 0 & 8 & 0 & 0 & 3 & 17 & 1 & 34 \\
\hline 2000 & 14 & 0 & 6 & 4 & 2 & 4 & 24 & 0 & 54 \\
\hline 2001 & 9 & 1 & 1 & 2 & 4 & 4 & 13 & 0 & 34 \\
\hline 2002 & 13 & 1 & 6 & 4 & 0 & 2 & 10 & 0 & 36 \\
\hline 2003 & 9 & 2 & 9 & 4 & 0 & 1 & 7 & 60 & 92 \\
\hline 2004 & 7 & 0 & 4 & 5 & 3 & 4 & 2 & 23 & 48 \\
\hline 2005 & 8 & 0 & 19 & 1 & 3 & 1 & 7 & 4 & 43 \\
\hline TOTAL & 271 & 42 & 132 & 64 & 33 & 87 & 146 & 88 & 863 \\
\hline TOTAL & 31,40 & 4,87 & 15,30 & 7,42 & 3,82 & 10,08 & 16,92 & 10,20 & 100 \\
\hline
\end{tabular}

Fuente: Dirección General de Protección Civil y Emergencias, Anuario del Ministerio del Interior; elaboración propia.

El segundo episodio de inundaciones que marcó otro año catastrófico se produjo el 6 de noviembre de 1997, cuando en el barrio el Cerro de los Reyes, situado en las afueras de la ciudad Badajoz, se produjeron veinticinco fallecidos. Esta cifra fue la que hizo aumentar hasta cuarenta el número de fallecidos por inundaciones en aquel año, muy superior también al promedio señalado en el periodo estudiado (dieciséis). El tercer episodio que hizo aumentar el número de víctimas por encima de la media, hasta veintidós, fue el que se produjo el diecisiete de junio de 1995, cuando un depósito de agua situado en el municipio de Yebra (Guadalajara), se llenó hasta rebosar y al no poder aguantar toda el volumen de líquido se rompió inundando varios barrios hasta ocasionar la muerte a diez personas (véanse figuras 1 y 2 ).

Ya con posterioridad, durante 2000 y 2002 se registró un número importante de víctimas mortales, con catorce y trece, respectivamente, que originaron un nuevo pico en la evolución del número de fallecidos, pero representando una cifra situada por debajo del promedio del periodo estudiado (véase cuadro 1). De nuevo, la presencia de sendas DANA, en el año 
2000 fueron el origen de diversos episodios de lluvias torrenciales que causaron unas corrientes de agua que arrastraron literalmente a cuatro personas el once de junio en la ciudad de Barcelona; a otras cinco el veintidós de octubre en Tarragona y otras tres víctimas mortales en Murcia, el veintitrés de ese mismo mes. Ya en el año 2002, el uno de abril, otro episodio arrasaba el barrio de la Alegría, en Santa Cruz de Tenerife y dejaba nueve víctimas mortales (véanse figuras 1 y 2).

Figura 1. Número de falleCidos POR inUNDACIONES Y DESLIZAMIENTOS DE TERRENOS. ESPAÑA 1990-2005

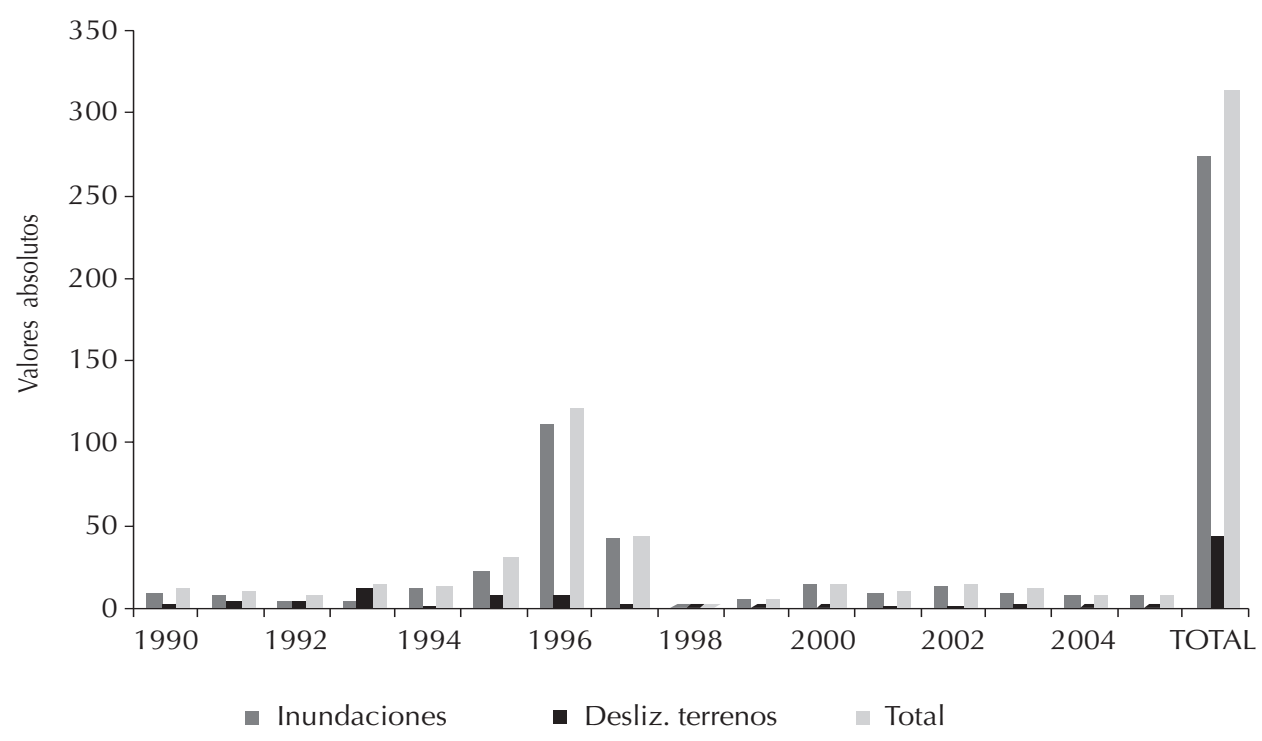

Fuente: Anuarios del Ministerio del Interior; elaboración propia.

A la vista de lo señalado, se observan varias características en relación a los fallecimientos ocasionados por las inundaciones en España. En primer lugar, en un solo episodio, este riesgo puede dejar sin vida a un importante número de personas. Este hecho es lo que ha determinado que haya sido tan elevadas las víctimas mortales, en algunos años, a la vez que ha supuesto la superior proporción del total de fallecidos, en relación con el resto de riesgos naturales, en el periodo estudiado 31,4\% (véase figura 2). En segundo lugar, los fallecimientos se producen generalmente porque la avenida torrencial de las aguas arrastra, literalmente, a las personas hasta producirles la muerte por ahogamiento. 
Figura 2. Número de falleCidos POR inUndACIONES Y DESLIZAMientos DE TERRENOS. ESPAÑA 1990-2005

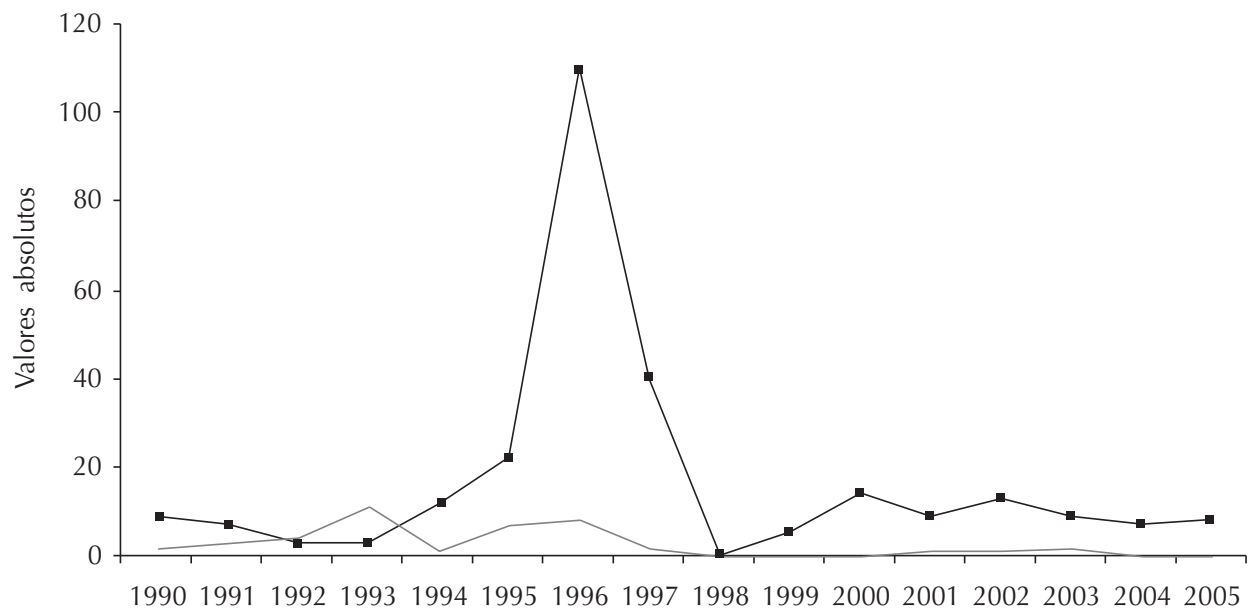

$\longrightarrow$ Inundaciones

Fuente: Anuarios del Ministerio del Interior; elaboración propia.

Realizando el análisis de víctimas mortales por provincias y teniendo en cuenta la valoración realizada hasta ahora, se observa que, lógicamente, la provincia con mayor número de víctimas mortales por inundaciones ha sido la de Huesca debido al accidente de Biescas; a continuación le sigue la provincia de Badajoz, en cuyo total también ha quedado reflejado el accidente ocurrido en la ciudad en el año 1995 y que ya ha sido señalado más arriba. A estas dos provincias le sigue en importancia Barcelona, en donde se produjeron otros episodios de inundaciones que dejaron, en total, veinticuatro fallecidos. De igual manera, destaca la provincia de Santa Cruz de Tenerife con trece víctimas mortales, de los cuales nueve de ellos se produjeron en la señalada inundación del treinta y uno de marzo de 2002. Asimismo, Tarragona presenta también una cantidad importante de fallecidos con trece y las provincias de Jaén, Málaga y Guadalajara son las que más destacan al presentar más de diez víctimas mortales en el periodo estudiado (véase figura 3).

A la vista de los datos analizados, se puede afirmar que utilizando el indicador de víctimas mortales, el de inundaciones ha sido, sin lugar a dudas, el riesgo natural más perjudicial para la población en España, durante los dieciséis años estudiados (véanse cuadro 1 y figura 3). 
FIGURA 3. NúMERO DE FALLECIDOS POR INUNDACIONES EN LAS PROVINCIAS ESPAÑOLAS DURANTE 1990-2005

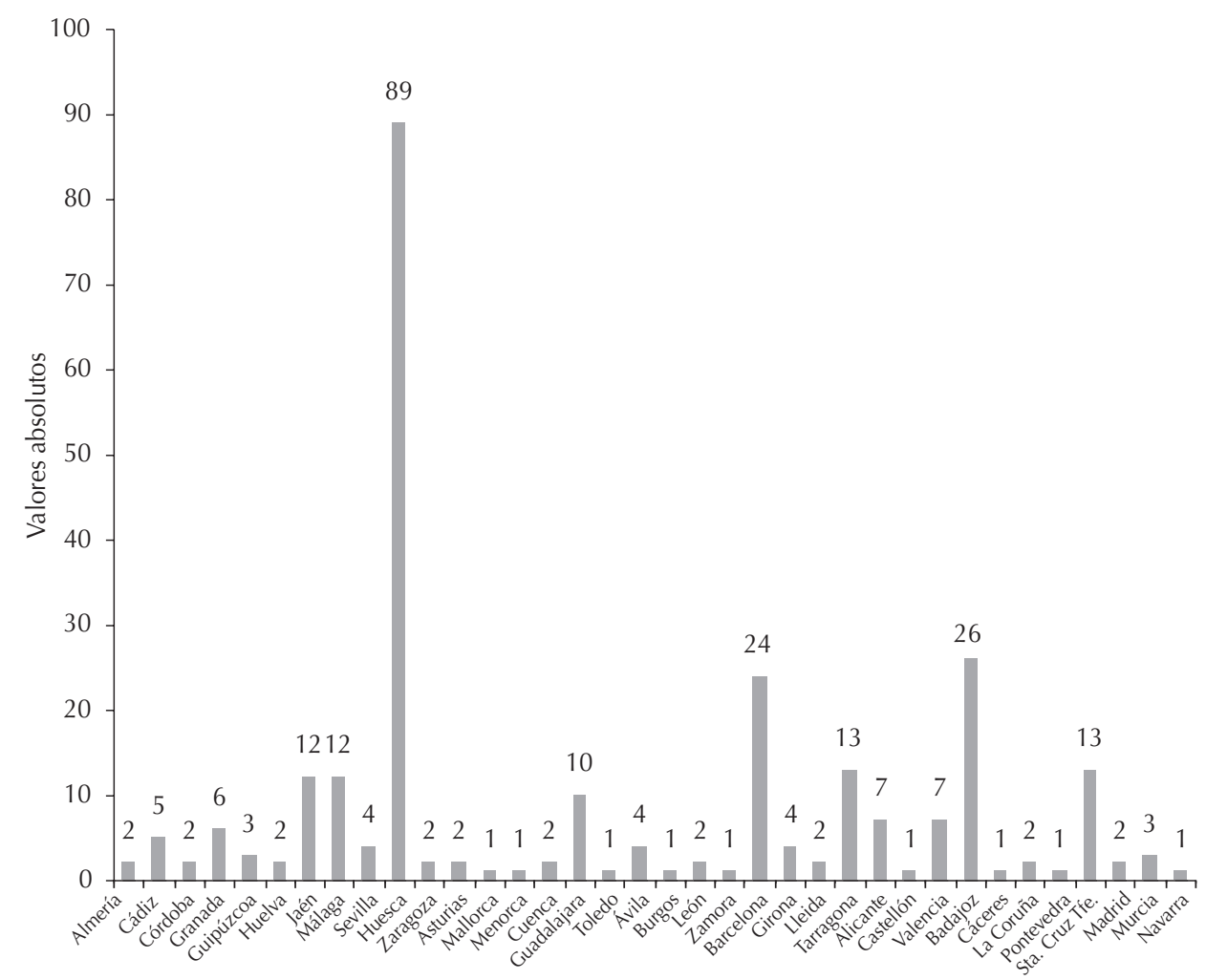

Fuente: Anuarios del Ministerio del Interior; elaboración propia.

\section{Las pérdidas económicas}

Otro indicador para valorar el daño que las inundaciones causan sobre las personas, consiste en realizar hacer el cálculo de las pérdidas económicas, en daños materiales, que surgen después de un episodio de lluvias torrenciales. Este aspecto siempre es muy difícil de estudiar, ya que a la hora de cuantificarlas, tanto las personas físicas como instituciones gubernamentales, tienden a valorar siempre, los daños, por encima, con el fin de conseguir mayores subvenciones económicas. No obstante, hay distintos elementos de análisis indirectos a los que nos podemos acercar para valorar las pérdidas económicas. Uno de ellos es estudiar la cantidad monetaria que las instituciones públicas han destinado a la población en concepto de indemnizaciones y subvenciones, con motivo de socorrerla después de un 
episodio de riesgos naturales que hayan originado cuantiosas pérdidas en vidas humanas o en bienes materiales. Como se ha señalado más adelante las ayudas económicas que se estudian en este artículo son las que ha gestionado el Ministerio del Interior, a través de la Dirección General de Protección Civil y Emergencias, que a su vez las ha canalizado a través de corporaciones locales, por gastos que hayan podido tener ante una emergencia; de empresas privadas y familias afectadas por los daños que hayan sufrido en viviendas no estructurales y daños en enseres y de personas físicas o jurídicas.

En la figura 4, se muestra todas las cantidades que la Dirección General de Protección Civil y Emergencias, del Ministerio del Interior, ha abonado una vez han sido ejecutados los expedientes. Pues bien, la mayor parte de las ayudas aprobadas y gestionadas se ha dirigido a pagar daños causados a la población por inundaciones, o bien por episodios de lluvias intensas acompañadas de vientos fuertes y tormentas (véase apéndice 1).

De todas las cantidades que han sido abonadas, en euros, caben destacar, en primer lugar, los créditos y subvenciones otorgados durante los años 1993,1994, 1999 y 2000, para compensar así a la población por los daños sufridos derivados del derrumbamiento de la presa de Tous ${ }^{6}$. De esta manera, una vez realizados y completados todos los expedientes pertinentes, sobre la base del Real Decreto-Ley de 4/1993 de 26 de marzo, la Ley 10/1995, de 28 de diciembre, y la Ley 28/1999, de 16 de julio, se han Ilegado a pagar, en total durante los años citados, una cantidad de casi ciento treinta millones de euros (véase figura 4 y apéndice 1 ).

Junto a estas cantidades, se han representado las abonadas por otros episodios catastróficos que han causado daños a la población en España en el periodo estudiado, entre los que sobresalen los pagos realizados para reparar los daños causados por la inundación que sucedió en Biescas (Huesca) el siete de agosto de 1996, de acuerdo con lo estipulado en el Real Decreto-Ley 13/1996, de 20 de septiembre por el que se llegaron a pagar cerca de veinticuatro millones de euros, durante los años 1996 y 1997 y las indemnizaciones que se realizaron de acuerdo a lo dictaminado en el Real

6. Como todos sabemos la presa de Tous tenía una capacidad de $80 \mathrm{hm}^{3}$; y se derrumbó la tarde del 20 de octubre de1982, debido a la descomunal crecida del río Júcar, debido a unas Iluvias torrenciales generadas por una DANA, ya desde el día anterior que descargó más de $600 \mathrm{~mm}$ en un área de $700 \mathrm{~km}^{2}$ aguas arriba del pantano. Al no poder abrirse las compuertas de la presa, ésta se colmató con un volumen excesivo de agua que al no poder aguantar y romperse, descargó un caudal, de aproximadamente $16.000 \mathrm{~m}^{3} / \mathrm{s}$ en Alcira, aguas abajo del embalse, dejando más de treinta muertos y una gran cantidad de daños materiales. 
Decreto-Ley 24/1997, para sufragar daños acontecidos por las inundaciones ocurridas en Extremadura en 1997 y que se abonaron durante los años 1998, 1999, 2000 (véanse figura 4 y apéndice 1).

Si se hace un análisis observando la evolución de las cantidades pagadas en concepto de ayudas a la población por años se aprecia que las mayores cantidades de dinero se aportaron durante el año 1999, en el que se llegó a pagar un total anual de casi sesenta millones de euros. De nuevo, durante los años 1993 y 1994 se abonaron, anualmente, hasta treinta millones de euros. Un tercer pico de aportación monetaria, aunque inferior a los dos periodos anuales señalados, se efectuó durante los años 1996 y 1997, cuando se abonaron ocho y quince millones de euros, respectivamente, dentro de las cuales se incluyen las que se pagaron por indemnizaciones por la catástrofe de Biescas (véase figura 5).

Figura 4. SubVEnCIONES ECONÓMICAS APORTADAS (EN EUROS), PRINCIPALMENTE, EN CONCEPTO DE INUNDACIONES

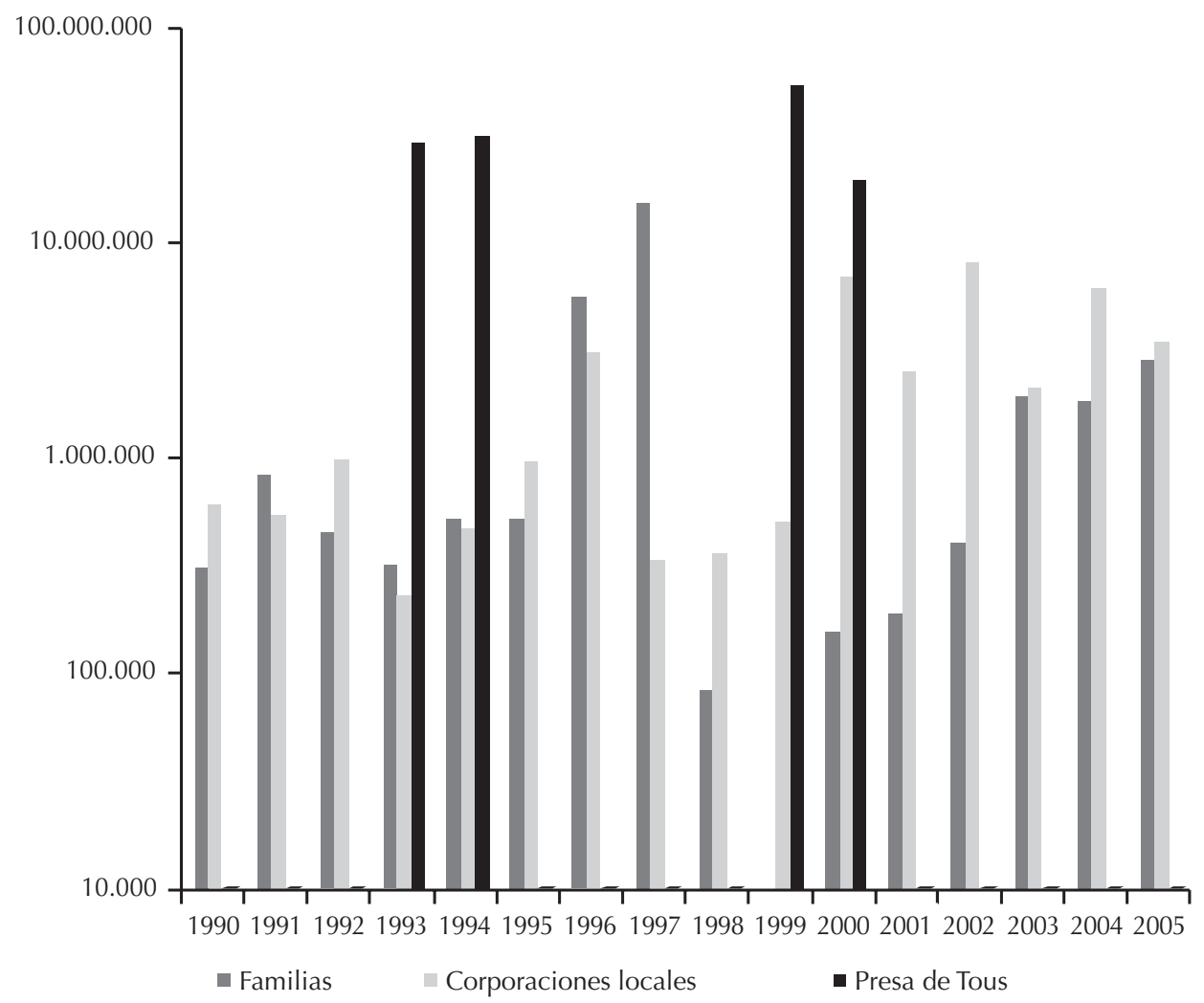

Fuente: Ministerio del Interior, Dirección General de Protección Civil y Emergencias; elaboración propia. 
Ya con posterioridad a los años señalados, de nuevo se vuelve a ver un pico en el año 2002, en el que se incluían las indemnizaciones que se dieron sobre la base de lo dispuesto en el Real Decreto-Ley 2/2002, por el que se concedían medidas urgentes para reparar los daños causados por las Iluvias torrenciales acaecidas el treinta y uno de marzo de 2002 en Santa Cruz de Tenerife y en San Cristóbal de la Laguna y que Ilegaron a alcanzar casi los diez millones de euros (véase figura 5).

Estas elevadas cantidades de dinero abonado en esos años nos acerca a una valoración aproximada sobre las cuantiosas pérdidas, en vidas humanas y materiales, que se pagó a la población afectada de las distintas provincias españolas, principalmente por lluvias torrenciales-inundaciones (véase cuadro 2). Si a dicha valoración le añadimos lo que se ha puesto de manifiesto a través del indicador sobre el número de víctimas mortales, se puede afirmar que el riesgo de inundaciones es el que más daño ha causado a la población, en el periodo estudiado.

FigurA 5. SUBVENCIONES ECONÓMICAS (EN EUROS) APORTADAS EN CONCEPTO DE INUNDACIONES

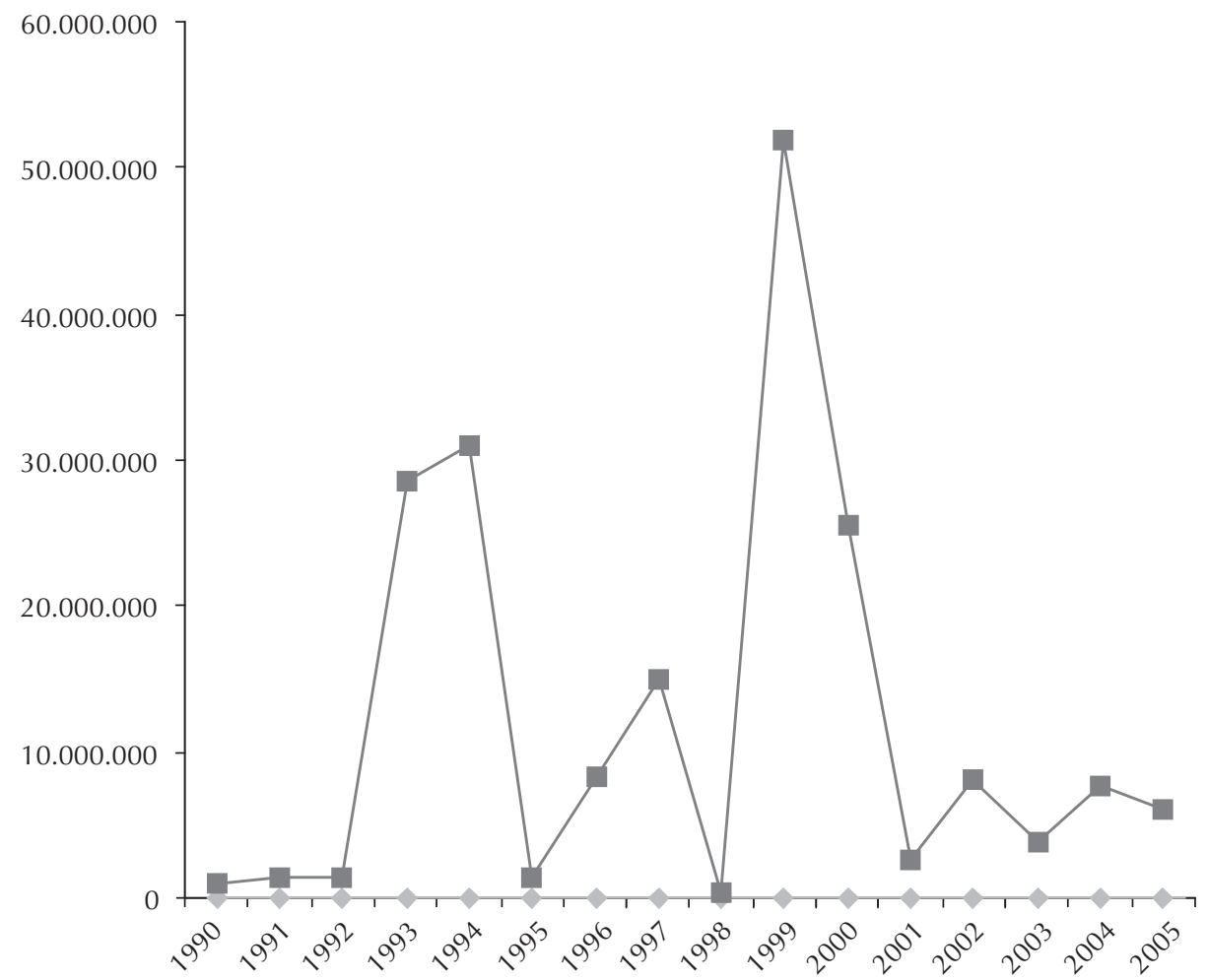

Fuente: Ministerio del Interior, Dirección General de Protección Civil y Emergencias; elaboración propia. 
Una vez demostrado dichos daños, se observa que se vuelven a repetir accidentes, semejantes a otros acontecidos con anterioridad y que la población sigue siendo altamente vulnerable a este riesgo, sobre todo en áreas urbanas. El porqué de este aspecto es lo que se analizará en los siguientes apartados.

\section{LA VULNERABILIDAD EN LAS ÁREAS URBANAS}

Analizando la vulnerabilidad, se puede afirmar que hay tantas interpretaciones sobre ella como investigadores de riesgo (Cutter, S. L., 1993); pero si se tiene como objetivo el análisis de las áreas urbanas, es necesario fijarse en que existen determinados sectores (barrios, distritos, etc.) de la ciudad, cuya vulnerabilidad, desde el punto de vista de la exposición al riesgo, es mayor en unos que en otros. Esta mayor vulnerabilidad estaría estrechamente ligada a una situación de desventaja o debilidad, desde un punto de vista económico o social originada a partir de una combinación de estructuras sociales y políticas, dando como resultado grupos de población vulnerable a escala de barrio, distrito, etcétera.

Junto a este factor se observan otros diversos que unidos a él agravan los daños ocasionados por las inundaciones en áreas urbanas. Así, las ciudades son lugares de alto riesgo, ya que la concentración de los hombres está considerada como una primera fuente de aumento de la vulnerabilidad. (Dauphiné, A., 2001).

Además la urbanización multiplica los daños que puedan causar las aguas de lluvias intensas debido a:

1. La extensión considerable de superficie de suelo urbano que tiene un coeficiente de retención muy débil debido al incremento del agua de las arrolladas y a la rapidez y aceleración del fluido, discurriendo sobre todo por antiguas ramblas, barrancos que en el momento actual ya se han convertido en "cauces" asfaltados.

2. Las precipitaciones importantes engendran rápidamente fuertes caudales que no pueden evacuar normalmente por salidas naturales o artificiales, máxime si dichas salidas no están bien limpias o colmatadas en el momento de la arrollada, o bien están ocupados por la construcción de edificios de residencias, de industrias, obras de infraestructura, etc. 
Por otra parte, después de que ocurra una inundación en el centro de la ciudad es normal que se produzca los desbordamientos en las periferias urbanas, sobre todo si la ciudad se encuentra rodeada de arroyos normalmente secos que se transforman en torrentes de un intenso caudal después de un episodio de lluvias intensas. Si en esas mismas áreas se suprimen o colmatan las salidas tradicionales de evacuación de las aguas, se incrementa el daño ocasionado por las inundaciones. Así pues, los daños ocasionados por aquellas se agravan en función de las topografías locales y a las modificaciones que la población impone a las salidas naturales (Dauphiné, 2001).

Junto a lo ya señalado, en las ciudades, una urbanización mal ubicada origina la colmatación de cauces así como la instalación de drenajes artificiales que no tienen la dimensión necesaria para responder a caudales punta, lo que ocasiona la invasión por las calles de riadas de fango, al mismo tiempo que se obstruyen las redes de saneamiento, sobre todo el alcantarillado, de tal manera que los barrios más afectados serán los de más reciente construcción y los más periféricos, los de creación espontánea, no reglamentados y los emplazados en vertientes de laderas, cuyas redes de saneamiento no se adaptan bien al crecimiento del nuevo barrio, o descuidan su limpieza, colmatándolas y obstaculizando con ello el discurrir de las aguas por su cauce.

Otro factor que contribuye al incremento de los daños originados por las inundaciones en áreas urbanas, proviene de la deforestación excesiva en las laderas de cuenca, que generalmente se producen como fruto de estrategias económicas a corto plazo o bien de incendios forestales. Junto a éste cabe señalar lo que se ha denominado planificación imprudente, a partir de un exceso de confianza en las técnicas de prevención, lo que puede originar la localización de instalaciones urbanas de gran riesgo. Este sería el caso de la urbanización en cauces de ríos, en los que se estima tener previsto el periodo de retorno de las inundaciones, sobre todo cuando los terrenos a utilizar son baratos, o bien se trata de terrenos aceptados por imperativos turísticos (Chaline, C. y Dubois-Maury, J., 1994).

\section{Algunos casos sobre daños en áreas urbanas originadas por inundaciones}

En los cuatro casos de inundaciones urbanas que se exponen a continuación vamos a ver si se han originado por uno o varios de los factores que se han señalado con anterioridad; no obstante, conviene mencionar muy 
sucintamente el mecanismo de la génesis de las lluvias intensas, responsables de las inundaciones.

\section{El origen de lluvias intensas en áreas urbanas}

La génesis de las Iluvias intensas en España obedece, generalmente, a la existencia de una Depresión aislada en niveles altos (DANA), más conocida, aunque denominada inadecuadamente, como Gota Fría en altura (Olcina Cantos, J., 2006). Ésta se origina a partir de la formación de una vaguada, que puede llegar a estrangularse quedándose aislada, en el discurrir del Jet Stream, dentro de la circulación general del oeste. Este proceso produce una fuerte exageración del gradiente térmico vertical, con el ascenso muy violento de la masa de aire de superficie, la cual, generalmente, se encuentra más caliente debido, o bien a que está situada sobre el mar mediterráneo, en donde nos encontramos con una masa caliente y muy húmeda (Tullot, F.,1983), que tiene más capacidad de conservar temperaturas más calidas sobre todo en los primeros meses del otoño; o bien a que existe una masa de aire más cálida en superficie, en contraste con la presencia de una masa de aire muy fría en altura.

Todo este proceso se ve acelerado, además, por la presencia de cordilleras, cuyo efecto orográfico potencia aún más el ascenso súbito y violento de la masa de aire, empujada asimismo por vientos del este. De esta manera, el vapor de agua se va condensando al encontrarse con la zona fría, formando cúmulo-nimbos que se van agrandando a gran velocidad, a medida que ascienden. Ello origina que en muy pocas horas se puedan formar grandes nubes tormentosas, que aunque no tengan una gran extensión en horizontal, pueden llegar a tener más de diez kilómetros de altura; con estas condiciones se producen lluvias muy intensas en muy poco tiempo. Todo ello trae como consecuencia la presencia de chubascos y tormentas de extraordinaria violencia, aunque de corta duración en el tiempo, que provocan Iluvias torrenciales, muy intensas, que afectan, normalmente, a áreas espaciales poco extensas. La situación meteorológica de DANA es muy frecuente en las zonas costeras del Mediterráneo, sobre todo entre los meses de septiembre a noviembre, pero pueden desarrollarse también en otros marcos espaciales y temporales, como veremos.

Los cuatro ejemplos que se explican a continuación obedecen a situaciones meteorológicas de DANA en España, las cuales, tras su paso, dejaron grandes daños en vidas humanas y enseres materiales. 
Estudio de casos de vulnerabilidad ante el riesgo de inundaciones, a escala local

Badajoz: la inundación del 7 de noviembre de 1997

Un fuerte temporal de lluvia y viento afectó de forma muy violenta el 7 de noviembre de 1997, dejando veintiuna víctimas mortales en el barrio del Cerro de los Reyes, en la ciudad de Badajoz.

La previsión meteorológica para las primeras horas del 6 de noviembre de 1997 anunciaba precipitaciones, ocasionalmente, fuertes y tormentosas. El temporal de viento y lluvia azotó a toda Extremadura registrándose 122 $\mathrm{l} / \mathrm{m}^{2}$ en Badajoz y $129 \mathrm{l} / \mathrm{m}^{2}$ en Cáceres. A partir de esta situación, hacia las dos y media de la madrugada del día 7 , arroyos y ríos, que generalmente discurren secos y sin regulación, comenzaron a crecer con las intensas lluvias que caían, hasta convertirse en torrentes, que acarreaban aludes incontenibles de agua y lodo.

El temporal alcanzó su punto más violento en las primeras horas de la madrugada, en la barriada del Cerro de los Reyes, una zona marginal de la capital pacense, situada muy cerca de los arroyos Calamón y Matamoros, y en la de San Roque. Ambas barriadas, junto con la de Pardaledas, surgieron en el extrarradio de la ciudad de Badajoz en los años sesenta, como consecuencia del éxodo rural a las ciudades (véase figura 6). Y así, quedaron situadas, en la confluencia del arroyo Rivillas con el Calamón, poco antes de su desembocadura en el río Guadiana. Los nuevos terrenos, ocupados progresivamente, sin actuación urbanística municipal, se fueron extendiendo por el cauce de los arroyos señalados de forma desordenada, lo que originó la carencia de infraestructuras mínimas urbanísticas e impidió un desarrollo socioeconómico integrado en esa zona.

Ante la presencia de este episodio de lluvias extremas, los cauces del Rivillas y del Calamón comenzaron a crecer hasta alcanzar los tres metros de altura. La avalancha de agua y barro golpeó brutalmente las viviendas de tal manera que sus habitantes (adultos, ancianos y niños) quedaron atrapados en sus casas. Algunos, posiblemente, perecieron sin salir aún de la cama.

Asimismo, la población de Valverde de Leganés (3.700 habitantes) fue también la que más sufrió los efectos del temporal. La localidad resultó arrasada; tres mujeres perecieron atrapadas por el agua y el barro y alrededor de ochenta personas, la mayoría niños y ancianos, tuvieron que refugiarse 
en la iglesia y en el Ayuntamiento. El agua superó los tres metros de altura, Ilevándose viviendas, automóviles y animales 7.

Ante esta hecatombe, inmediatamente surgieron las medidas de respuesta de emergencia ante la catástrofe, que se tradujeron en la realización de labores de rescate, en las que participaron más de tres mil personas entre las que se encontraban las Fuerzas Armadas, Guardia Civil —desplegó en la zona más de setecientos agentes- Policía Nacional, Cruz Roja, Protección Civil, Bomberos y otros organismos que se sumaron a las tareas de rescate. Desde Sevilla se incorporaron dos unidades policiales y quince agentes de los Grupos Especiales Operativos (GEO), así como el Centro de Instrucción y Movilización de Cáceres (CIMOV) y los regimientos Saboya y Castilla, todos los cuales se vieron con dificultades en su actuación por la incomunicación en la que se encontraba la provincia de Badajoz.

Asimismo y como una medida de respuesta más, el gobierno aprobó el Real Decreto-Ley 24/1997 por el que se adoptaron medidas urgentes para reparar daños causados por inundaciones y temporales de vientos acaecidos el 5 y 6 de noviembre de 1997, por Vientos e Inundaciones en Extremadura, de quinientos cinco mil euros, más unas obligaciones de ciento ochenta y cinco mil euros a pagar a largo plazo, que se ejecutaron durante el año 2000.

Éste es, pues, un ejemplo en el que las Iluvias torrenciales generaron inundaciones por desbordamientos de arroyos que, normalmente están secos y que se transforman en torrentes de un intenso caudal después de un episodio de lluvias intensas. Dichos desbordamientos afectaron a barrios de construcción espontánea, no reglamentados y situados en los márgenes de sus laderas y en la periferia de la ciudad de Badajoz, en este caso. Así pues, aquí hallamos un claro ejemplo de vulnerabilidad por la exposición de la población a unas zonas de riesgo, con la permisividad, consciente o no, de las instituciones públicas.

7. Según declaraciones de los vecinos, todo ocurrió en segundos. El desastre llegó de pronto, sin que nadie pudiera preverlo. La riada entró en las viviendas, por puertas y ventanas al mismo tiempo que el agua sacaba muebles, electrodomésticos y enseres que se incrustaban violentamente contra otras viviendas. Se derrumbaban los tabiques y los vehículos aparcados en la calle se empotraban contra las casas. Cuando la avalancha de agua destrozó puertas y ventanas y anegó las primeras plantas de las casas, la gente trató de alcanzarlos pisos altos, las terrazas y los tejados en un intento de situarse a salvo y de huir de la catástrofe. 
Tenerife: inundaciones en las laderas del macizo de Anaga, el 31 de marzo de 2002

En este caso hay un episodio de lluvias intensas, que se inició el 31 de marzo de 2002 en la ciudad de Santa Cruz de Tenerife y cuyas trágicas consecuencias se extendieron hasta el 10 de abril. Las Iluvias caídas, fueron de carácter torrencial, Ilegándose a alcanzar hasta $70 \mathrm{l} / \mathrm{m}^{2}$ en una hora, superando la predicción meteorológica de chubascos moderados (21-40 l/m² en una hora), que el Instituto Nacional de Meteorología (INM) había previsto para ese día. La célula de aire frío en altura se estabilizó, situándose, anómalamente durante horas, en el área de las laderas del macizo de Anaga, concretamente entre Santa Cruz de Tenerife y La Laguna.

Los efectos de dichas Iluvias torrenciales ocasionaron grandes desastres en la ciudad de Santa Cruz de Tenerife, entre los que destacan: el anegamiento de todo el centro urbano; el bloqueo de tres sectores de acceso a la ciudad, debido a que los barrancos de Santos y San Andrés seccionaron la ciudad originando la incomunicación de diversos barrios costeros como consecuencia del desprendimientos de terreno, cortes en el suministro eléctrico, que llegó a dejar sin agua y sin luz al ochenta por ciento de la población de la ciudad y el corte de diecisiete mil líneas de teléfono.

A estos daños producidos en los barrios señalados, hay que sumar otro muy importante, como fue la amenaza de desbordamiento de la presa Fumero, situada en el barranco de la Leña, que estuvo a punto de arrastrar los cimientos del edificio Barlovento, el cual había sido evacuado días antes. En efecto, la presa experimentó una subida muy importante de su nivel y corría el riesgo de desbordar $10.000 \mathrm{~m}^{3}$ de un primer tanque de agua, el cual arrastraría consigo un segundo tanque de $15.000 \mathrm{~m}^{3}$, si se desbordaba el primero. Ante esta situación los técnicos del Consorcio de Agua del Cabildo, previa evacuación de los residentes en los edificios próximos a la presa, redujeron el nivel del segundo tanque, mediante su drenaje natural, mientras que se intentaba rebajar el nivel del primero, a través de grandes tubos, junto al desmonte en un lateral de la presa, para poder efectuar drenaje reduciendo así el volumen de agua. Más tarde, la empresa TRAGSA optó por la demolición de la presa Fumero.

Este mismo episodio de lluvias intensas que se desencadenó el 31 de marzo de 2002 afectó también a los barrios de La Alegría, San Andrés8, Valleseco y otros sectores, situados en la vertiente del Macizo de Anaga, en

8. Para un mejor conocimiento de estos barrios, véase la publicación de Pulido Mañes, T. (1979). Véase bibliografía. 
los que las inundaciones se cobraron la vida de nueve personas y se evacuaron a otras quinientas. Se trata de barrios marginales de crecimiento espontáneo en la Isla de Tenerife con alta probabilidad de exposición ante el riesgo, debido a las pésimas condiciones de infrahabitabilidad, que no estaban preparados para soportar lluvias superiores a $90 \mathrm{l} / \mathrm{m}^{2}$ en una hora (véanse figuras 6 y 7 ).

En otros barrios de esta ciudad de Santa Cruz de Tenerife se ocasionaron, asimismo, serios daños en edificios situados sobre la Rambla General Franco y la Rambla Pulido, donde, en la primera, fue necesario evacuar un edificio de ocho plantas debido a una fuerte explosión que se produjo al haber cedido pilares de la estructura del edificio. Ramblas, ambas, que antes de urbanizarse la ciudad constituían antiguos barrancos convertidos ahora en cauces de asfalto, sin poder de retención de las aguas y, por el contrario, con poder de acción de velocidad de la crecida.

Figura 6. Foto del barrio de San Andrés, en la ciudad de Santa Cruz de Tenerife, AL FONDO. EN PRIMER PLANO, LA PLAYA DE LAS TERESITAS

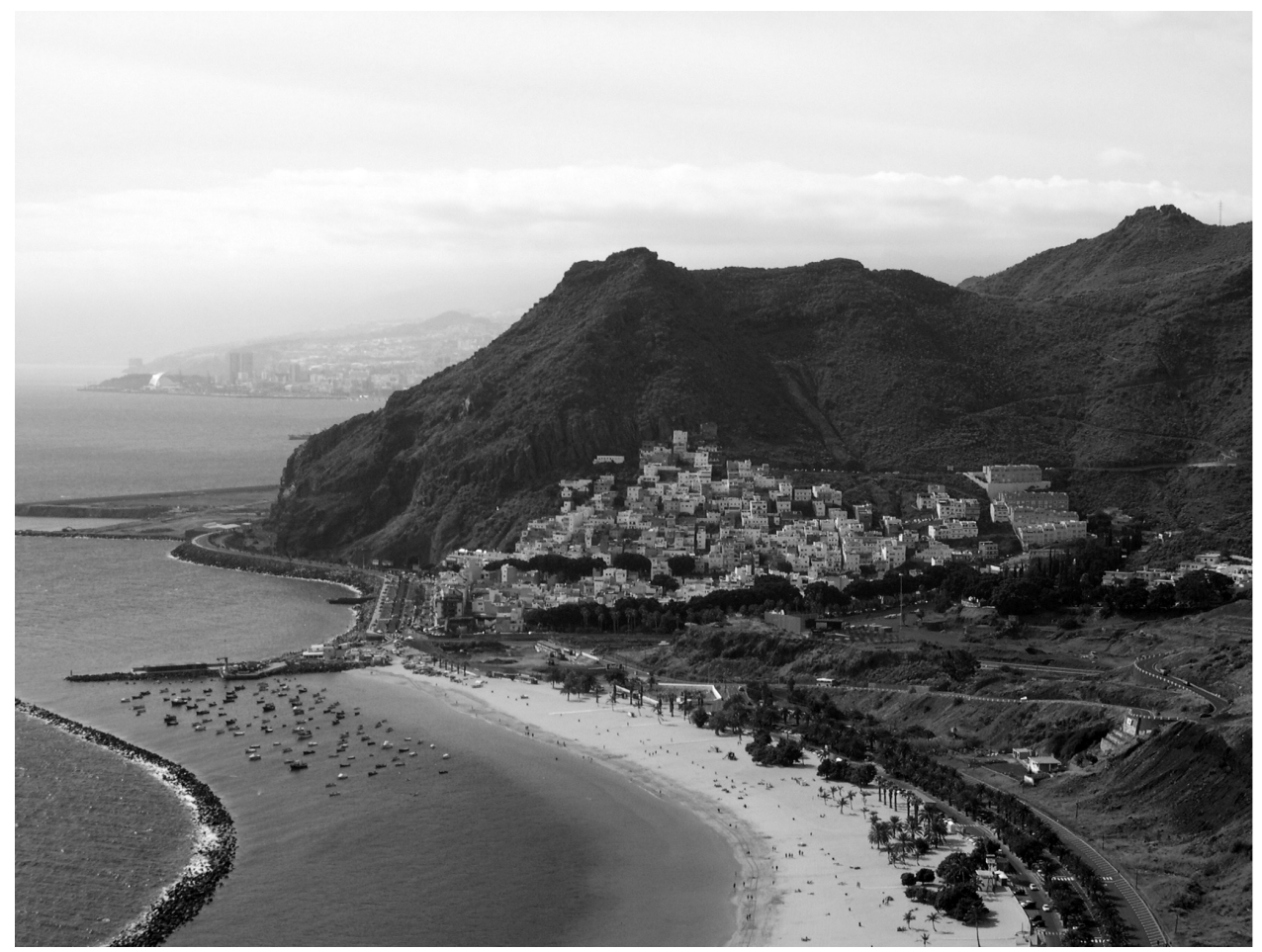

Fuente: Elaboración propia. 
Una vez más las medidas de respuesta urgentes para reparar los daños fueron inmediatas, a partir de la intervención del ejército en las labores de evacuación de la población, en el recinto ferial, habilitado para realizar las actividades de abastecimiento de medios extraordinarios, junto a la intervención de distintos Cuerpos de seguridad, como

Figura 7. Foto, en primer plano, del barrio de La Alegría, en la ciudad de Santa Cruz de Tenerife. Bajo la arboleda, el discurrir del barranco Tahodio

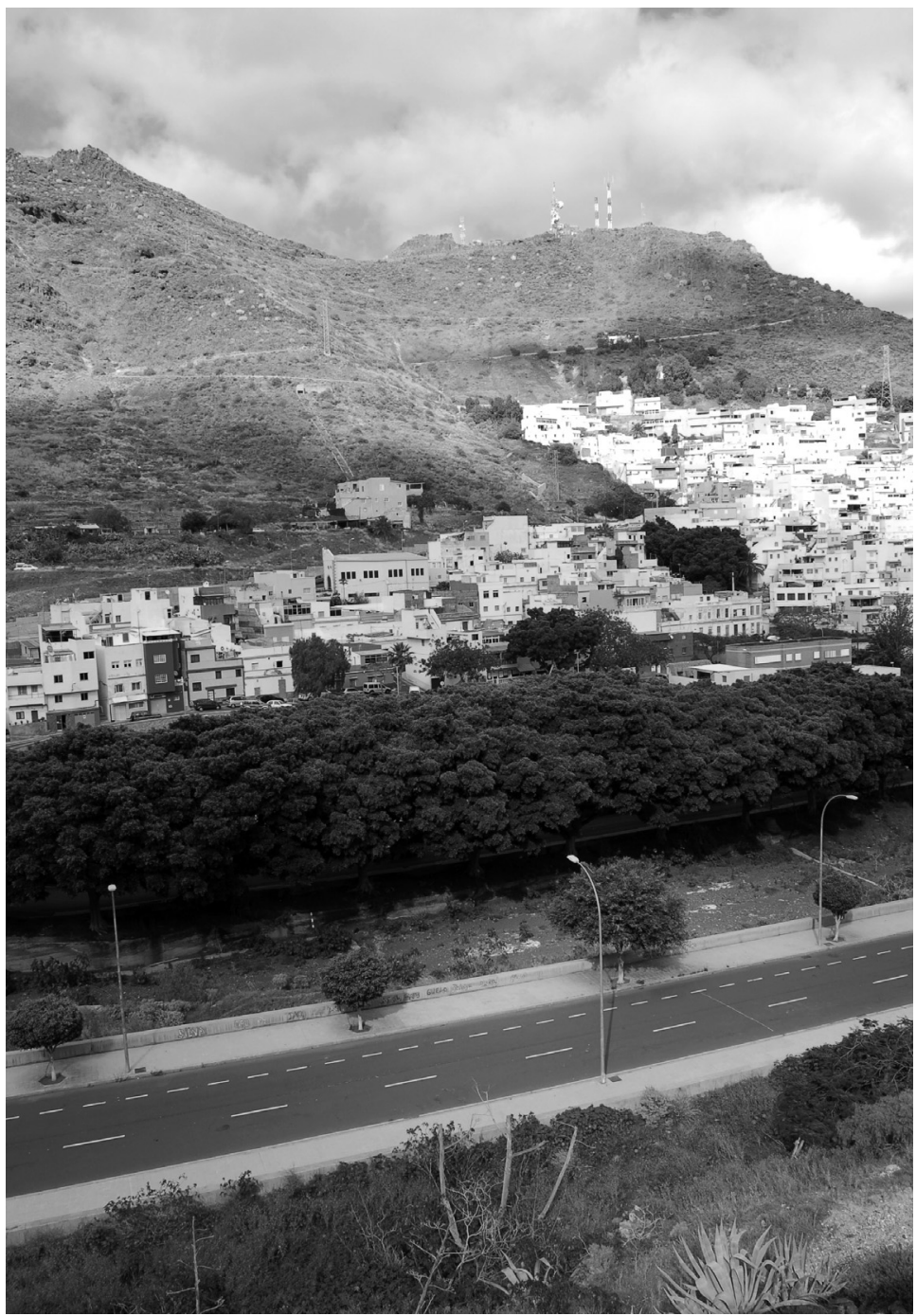

Fuente: Elaboración propia. 
Cuerpo de Bomberos, Servicio Canario de salud, Servicio de Emergencias del Gobierno de Canarias, voluntarios de Protección Civil y unidades de Cruz Roja. En este mismo ámbito de medidas de respuesta, se encuentra la aprobación por parte del Gobierno del Real Decreto-Ley 2/2002, sobre medidas urgentes para reparar los daños causados por las lluvias torrenciales acaecidas el 31 de marzo de 2002, en Santa Cruz de Tenerife y en San Cristóbal de la Laguna (Tenerife).

Este ejemplo, como el anterior, constituye, de nuevo, la vulnerabilidad ante los riesgos por exposición de barrios marginales, de construcción espontánea, no reglamentado urbanísticamente (Calvo GarcíaTornel, F., 2001): que han ocupado los terrenos más baratos y se han ubicado en la periferia de las ciudades, en este caso en la de Santa Cruz de Tenerife, junto a ramblas o barrancos habitualmente secas, que se transforman en torrentes (algunos convertidos ya en calles asfaltadas) después de fuertes lluvias. La localización de los barrios de San Andrés, La Alegría y Valleseco, de construcción espontánea, se encontraban obstaculizando las salidas tradicionales de evacuación de las aguas y de esta manera incrementaron los daños que ocasionaron las propias inundaciones. Asimismo en dichos asentamientos urbanos existían drenajes artificiales que no tenían la dimensión necesaria para responder a caudales punta que se produjeron, lo que dio lugar a la obstrucción de las redes de alcantarillado y a que se produjera la invasión, por las calles, de riadas de agua y de fango. De modo que estos peligros de lugar se han visto incrementados por la urbanización, en el hecho que las antiguas ramblas convertidas ahora en calles asfaltadas (en el caso de la ciudad de Sta. Cruz de Tenerife), tienen menos poder de retención de las aguas, con lo que se incrementa la velocidad de la corriente y con ello aumenta el daño de la riada en estos barrios marginales (véanse figuras 6 y 7 ).

En estos ejemplos expuestos, las autoridades políticas infravaloraron las medidas de prevención que existe ante la presencia de un episodio de Iluvias torrenciales. Se podía haber reducido la vulnerabilidad de la población allí residente, mediante la realización de mejoras en las condiciones de habitabilidad, adoptando medidas de prevención urbana conociendo el riesgo, a partir de la toma de conciencia de la localización de dichos asentamientos marginales sobre antiguos lechos de ríos. Por ello, las autoridades políticas debieron responder ante el riesgo adoptando medidas de respuesta urgentes ante la emergencia, como las que se han descrito. 
Málaga: inundación del 28 de marzo de 2004

El día 28 de marzo de 2004 se produjeron unas graves inundaciones en el municipio del Rincón de la Victoria y su pedanía La Cala del Moral, provocadas por unas intensas Iluvias torrenciales que Ilegaron a acumular 225 $\mathrm{l} / \mathrm{m}^{2}$ en doce horas. Este mismo municipio ya había sido afectado por otras Iluvias intensas el 28 de septiembre de 2001, pero, aquella ocasión, de nuevo volvía a padecer el desbordamiento de los numerosos arroyos que atraviesan su casco urbano; arroyos que se generan en la vertiente sur de la cordillera y desaguan en las playas malagueñas.

La inundación se produjo a partir de la cantidad de agua recogida en las cabeceras de los arroyos del Pollo, Totalán, de los Pinchos, del Cementerio, Pajarito, Granadilla, de las Cuevas y Benagalbón, arroyos todos ellos que, debido a su elevada probabilidad de desbordamiento ante la presencia de lluvias intensas, a partir del Decreto 189/2002, de 2 de julio ${ }^{9}$ se incluyeron en el Plan de Prevención de avenidas e inundaciones en cauces urbanos andaluces. Afortunadamente, el episodio de inundación de 2004 no produjo ninguna víctima mortal, pero los daños materiales fueron muchos y cuantiosos. La fuerza de la corriente arrastró enormes cantidades de depósitos sólidos, ramajes, piedras y otros elementos, resquebrajando las calzadas. El paseo marítimo, al estar construido en perpendicular a los arroyos, ejerció de represa, y hubo que limpiar el agua mediante bombas de achique, con el fin de evitar mayores daños. Además reventó el alcantarillado, se produjeron balsas de agua y árboles caídos en algunas carreteras comarcales y locales, inundaciones en sótanos, falta luz en algunos sitios del municipio y desalojos de, al menos, cincuenta viviendas de población.

Uno de los barrios más afectados fue el Ilamado de "Los Pescadores", ubicado en la antigua N-340, convertida ahora en vía urbana, y en el paseo marítimo, el cual, al estar construido de manera perpendicular a los arroyos, ejerció de represa obstaculizando la salida de las aguas al mar.

Entre las causas que contribuyeron a aumentar los daños del desastre se encuentran el inapropiado diseño de construcción del paseo marítimo, la escasa limpieza y deficiente drenaje de los cauces de estos arroyos, el abovedamiento de los tramos fluviales urbanos y la usurpación urbanística de terrenos de "Dominio Público Hidráulico". Se calcula que

9. Decreto 189/2002, de 2 de julio, por el que se aprueba el Plan de prevención de avenidas e inundaciones en cascos urbanos andaluces. 
las pérdidas pudieron alcanzar entre dieciocho y treinta millones de euros, mientras que el número de damnificados podría alcanzar la cifra de mil personas.

Tras la catástrofe (y como es lógico en un país desarrollado como España), se pusieron en marcha por parte de las autoridades, las medidas de respuesta ante la emergencia, de tal manera que quedó constituido el CECOPI (Centro de emergencia y de coordinación operativa integrado), el día 28 a las 12:30 horas, en la Delegación del Gobernación de la Junta de Andalucía, para coordinar las medidas de emergencia ante la catástrofe; así el día 30 de marzo, en el Rincón de la Victoria ya estaban todos los servicios restablecidos.

A diferencia de los casos anteriores, en el Rincón de la Victoria, no se puede hablar de la existencia de asentamientos de autoconstrucción o ilegales, pero si aparecen elementos que son comunes, como es el hecho que las fuertes precipitaciones que allí cayeron, generaron rápidamente enormes caudales en los lechos de los arroyos, los cuales no pudieron evacuarse normalmente por salidas naturales porque no estaban bien limpias y además habían quedado colmatadas por la construcción de un paseo marítimo; es decir, de una obra construcción humana que en el momento de la arrollada estaba obstaculizando la salida normal de las aguas, formando un represamiento artificial, con lo que los daños ocasionados por las inundaciones se agravaron en función de las topografías locales y por las "modificaciones que los hombres habían impuesto a las salidas naturales" (Dauphiné, A., 2003).

Huesca: inundación en Biescas el 7 de agosto de 1996

De nuevo fue debido a un proceso de DANA lo que ocurrió en Biescas, el 7 de agosto de 1996 (véase figura 9). Una vez más la penetración de una masa de aire muy cálida y húmeda desde el Mediterráneo juntos a la llegada de masas de aire frío en altitud fue lo que provocó una situación de gran inestabilidad. Esta situación no era desconocida en el barranco de Arás, donde se desencadenó la tragedia. De hecho, en agosto de 1942 ya se habían registrado $140 \mathrm{~mm}$ de lluvia en un día y en otros episodios de lluvias torrenciales se habían superado los $100 \mathrm{~mm}$ en veinticuatro horas (García-Ruiz et al., 2004).

Dado que el barranco de Arás ya había presentado una notable actividad torrencial, con avenidas muy frecuentes e intensas, en los años cincuenta, se hicieron unas obras de corrección sobre su cauce y su cono de 
deyección natural (muy activo geomorfológicamente) en el cual se construyó un canal artificial y escalonado trazado rectilíneamente, abandonándose así el cauce por el que discurría, de manera natural, en décadas anteriores. El nuevo canal artificial se prolongaba, aguas arriba, a través de un tramo canalizado y de una sucesión de casi cuarenta presas de retención de sedimentos (García-Ruiz y otros, 2004).

Confiando en estas obras y en tratar de impulsar el desarrollo turístico local, en el año 1987 se decidió, la instalación de un camping (de Las Nieves), entre el canal artificial y el anterior (natural). Se trató de la ubicación de un elemento de desarrollo turístico en un enclave paisajístico de gran belleza que, por estas mismas características, podía incentivar el desarrollo local de la zona a partir de la atracción de población a este lugar para pasar unos días de descanso

Las Iluvias caídas Ilegaron a alcanzar aproximadamente de $160 \mathrm{~m} 3 / \mathrm{s}$, pero la intensidad de la avenida, cerca del ápice del cono de deyección, se estima que alcanzó un caudal punta entre 200-600 m³/s (Benito, G. et al., 1998). El canal artificial no tenía capacidad nada más que para acoger una avenida entre 100-120 m³/s de tal manera que el agua buscó otra salida y la encontró en la explanada ocupada por el camping de Las Nieves, ocasionando ochenta y siete víctimas mortales.

En este ejemplo, a diferencia de los anteriormente expuestos, la infravaloración del peligro, que pudieran ocasionar unas posibles lluvias torrenciales, vino determinado por la unión de dos elementos: la acción de una planificación imprudente, junto a la presencia de un exceso de confianza en las técnicas de prevención, lo que originó la localización de esta instalación urbana (turística) de gran riesgo, sobre todo cuando los terrenos a utilizar eran baratos y además fueron aceptados por imperativos turísticos (Chaline, C., 1994).

Parte de lo anteriormente expuesto quedó corroborado por la sentencia de la Sala de lo Contencioso-Administrativo de la Audiencia Nacional que condenó al Ministerio de Medio Ambiente y a la Diputación General de Aragón ${ }^{10}$ a indemnizar de forma solidaria con un total de 11.265.987 euros, a los familiares de las ochenta y siete víctimas mortales. En ella se indicaba que tal y como había apuntado peritos que intervinieron en el proceso, el camping era una instalación "muy frágil" que ocupaba la parte más activa del cono de deyección o abanico aluvial de un barranco de fuerte torrencialidad.

10. La sentencia fue dictada por la Audiencia Nacional el 21 de diciembre de 2005 y publicada en los diarios de información el 22 de diciembre de 2005. 
Asimismo la sentencia eximió de responsabilidad a los otros dos demandados: al director del camping (Luis Bardají) y al Ayuntamiento de Bisecas, condenando, por el contrario al Ministerio de Medio Ambiente (del que depende la Confederación Hidrográfica del Ebro) y al Gobierno de Aragón, porque autorizaron o consintieron la adjudicación e instalación del camping cuando tenían medios suficientes para acreditar las condiciones y el riesgo que conllevaba la zona en la que se estableció:

"(...) Ya que, a la hora de elegir el emplazamiento de un camping, se debe buscar un lugar que impida un peligro para los acampados y para sus enseres y no se valoraron por las Administraciones Públicas legalmente obligadas a ello, y con los medios científicos y técnicos de que disponían, todas esas circunstancias expuestas y que era necesario apreciar cuando se autoriza o consiente una instalación de esas características en el lugar en el que se hizo."

"(...) El lugar en donde finalmente se colocó el camping no era el idóneo para la seguridad de las personas y de sus bienes, como luego lo confirmó una avenida que se produjo antes de transcurrir diez años desde que empezaron a funcionar sus instalaciones."

La sentencia declaró la responsabilidad solidaria de la Diputación General del Aragón y del Ministerio de Medio Ambiente, al considerar "(...) que no se puede individualizar la responsabilidad de cada una de estas administraciones". La primera fue la que autorizó la ocupación del monte en el que se situó el camping de "Las Nieves", sin cuya intervención el citado complejo "no podría existir". Por su parte, la Confederación Hidrográfica del Ebro, dependiente de Medio Ambiente, no autorizó expresamente esa ocupación pero "(...) consintió con actos posteriores y concluyentes su instalación y normal funcionamiento hasta la misma fecha en que ocurrieron los hechos".

Una vez más, ocurrida la catástrofe, el Gobierno adoptó diversas medidas de respuesta ante la emergencia, entre las que caben citar como más importantes, la aprobación del Real Decreto-Ley 13/1996, de 20 de septiembre, por el que se adoptaban medidas urgentes para reparar daños causados por la reciente inundación en Biescas (Huesca), que se tradujo en la concesión por parte del Ministerio del Interior (a través de la DGPCE) en subvenciones a unidades familiares y a personas físicas o jurídicas que fue pagado en el año 1997 (véase apéndice 1). 
Figura 8. Detalle de la situación general de Biescas, con respecto a la provincia DE HUESCA

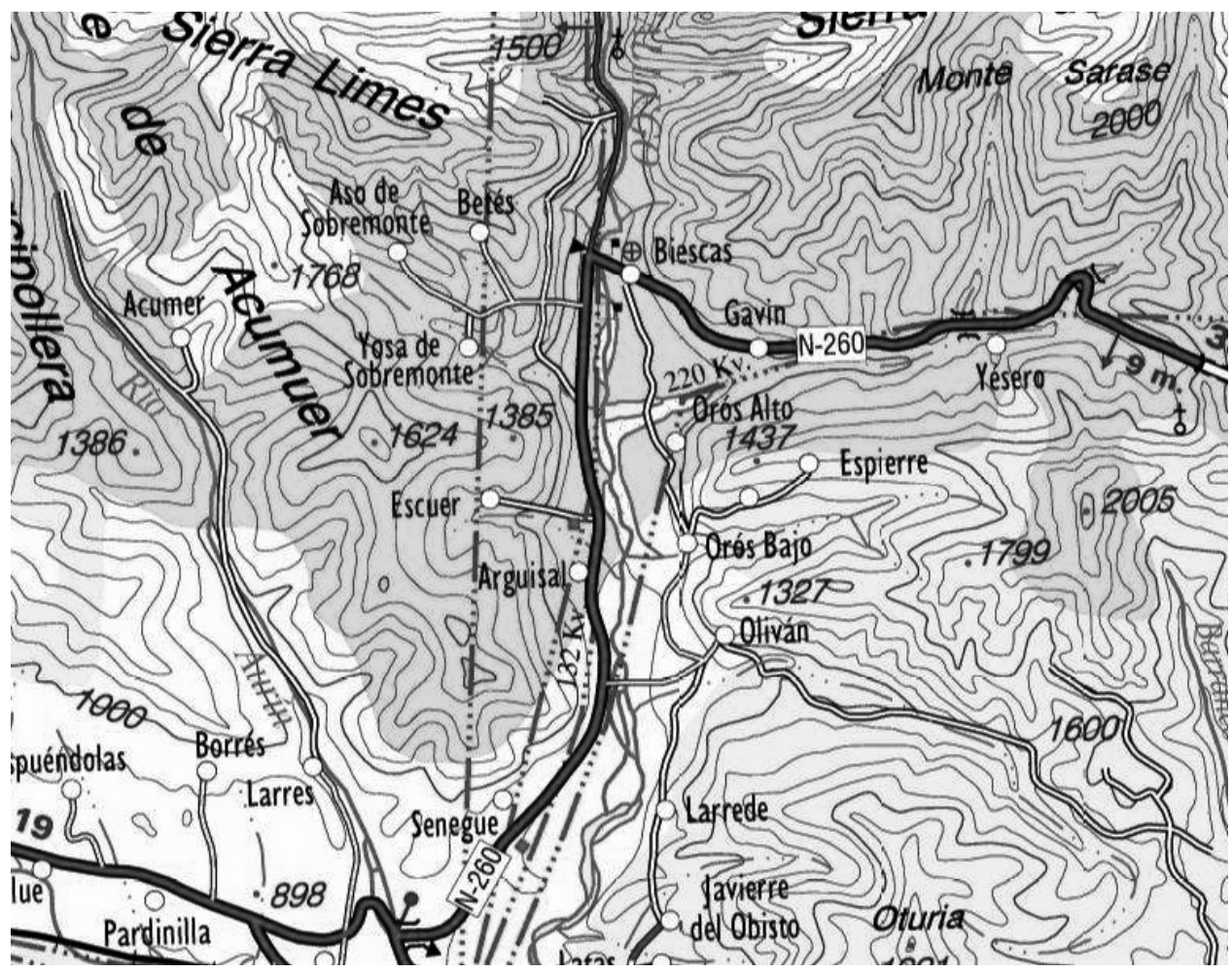

Fuente: Mapa de España. Carta digital E: 1.250.000.

\section{A MODO DE CONCLUSIÓN}

El riesgo de inundaciones, a pesar de haberse cobrado el mayor número de víctimas mortales y de pérdidas en bienes materiales, según datos suficientemente relevantes, puestos de manifiesto en diversas ocasiones y por distintos investigadores en la materia, constituye todavía un peligro cuyos daños son infravalorados tanto por las instituciones públicas, como por la población (desde una percepción subjetiva) y especialmente por aquellos habitantes que habitualmente residen en áreas en las que frecuentemente se producen Iluvias intensas.

Esta infravaloración del riesgo, desde el punto de vista de la percepción del mismo por parte de las autoridades, se traduce en la minimización de la adopción de medidas de prevención ante la presencia de un episodio 
de lluvias torrenciales, debido a un exceso de confianza en las medidas técnicas de respuesta y de defensa ante los daños que pueda ocasionar este peligro. Este exceso de confianza de las autoridades en los mecanismos de respuesta ante la presencia de peligros naturales es lo que ha incentivado la disposición de medidas de desarrollo local, en algunas ocasiones mal entendido, infravalorando la acción de los elementos naturales en situaciones extremas, como ocurrió en el camping de Las Nieves en el pirineo aragonés.

En las periferias de áreas urbanas de España se siguen produciendo crecimientos e incluso urbanizaciones espontáneas, que carecen de planificación urbanística, que se van asentando en terrenos muy baratos sin infraestructuras urbanas o muy poco consistentes, cuando existen, en donde las redes de saneamiento así como las salidas naturales del agua, en muchas ocasiones, se ven obstruidas por estas mismas construcciones y esto motiva la existencia de grandes inundaciones, en cuanto se produce un episodio de Iluvias torrenciales. Ello origina la existencia de una elevada vulnerabilidad social en determinados barrios o sectores urbanos, que obedece a un desigual nivel económico de sus habitantes.

A pesar de existir, en la normativa vigente de urbanismo de Comunidades Autónomas, artículos en los que se obliga a tener en cuenta la presencia de Riesgos Naturales en el proceso de planificación urbana de los terrenos, esto no se corresponde con la realidad y se sigue construyendo edificación urbana, residencial, industrial, etc. sobre antiguos lechos de torrentes y ramblas, aparentemente secos, sin considerar la naturaleza de los mismos en áreas de clima mediterráneo. Así se observa que, en la mayor parte de las ocasiones, la planificación urbana y la construcción real de la edificación siguen caminos diferentes, cuando no opuestos o contrarios.

Así pues, en algunos casos, lo establecido en los planes de emergencia de Protección Civil, (elaborados por todas las Comunidades Autónomas, previa homologación de la Comisión Nacional de Protección Civil), así como lo estipulado por la Directriz del riesgo de inundaciones y la adopción de medidas de prevención, ante la presencia de lluvias intensas y consecuentemente de las inundaciones generadas por las mismas, no resultan todo lo eficaces que debieran ser. 


\section{APÉNDICE}

\section{DeCRETOS-LeYES QUe AVALAN LAS CONCESIONES ECONÓMICAS}

REAL DECRETO- Pagado en 1993, Por el que se autoriza

LEY 4/1993, de 26 1994, $2000 \quad$ el resarcimiento de los daños

de marzo

causados como consecuencia

de la rotura de la presa de Tous

y se concede un crédito

extraordinario por importe

de 19.000 millones de pesetas.

LEY 10/1995, Pagado en 2000 De compensación de daños

de 28 de diciembre por la rotura de la presa de Tous.

LEY 28/1999, Pagado en 1999 Crédito extraordinario por

de 16 de julio importe de 9.393.184.038 de

pesetas para el pago de

indemnizaciones derivadas del

derrumbamiento de la presa de Tous.

\begin{tabular}{|c|c|c|}
\hline $\begin{array}{l}\text { ORDEN } \\
18-03-1993\end{array}$ & Pagado en 1995 & $\begin{array}{l}\text { Que regula procedimiento } \\
\text { para la concesión de ayuda } \\
\text { en atención a determinadas } \\
\text { necesidades derivadas de } \\
\text { situaciones de emergencia, } \\
\text { catástrofes y calamidades } \\
\text { públicas. }\end{array}$ \\
\hline
\end{tabular}

Subvenciones a
Corporaciones Locales por
gastos de emergencia o
suministro de agua
potable.

Requerimientos a empresas privadas para realizar una prestación personal o de bienes en materia de protección civil.

Subvenciones a familias por daños en vivienda, no estructurales y daños en enseres.

\begin{tabular}{llll}
\hline LEY 9/1995, de 8 & Pagado en 1996 & $\begin{array}{l}\text { Subvenciones a familias } \\
\text { y Unidades de Convivencia }\end{array}$ & Subvenciones a Unidades \\
Fe septiembre & & Familiares y a Personas
\end{tabular}
por situaciones de emergencia, Físicas o Jurídicas a Catástrofe o Calamidades Públicas. Castilla-La Mancha.

ORDEN 18-03-1993 Pagado en 1996

Que regula procedimiento para la concesión de ayudas en atención a determinadas necesidades derivadas de situaciones de emergencia, catástrofes y calamidades públicas.

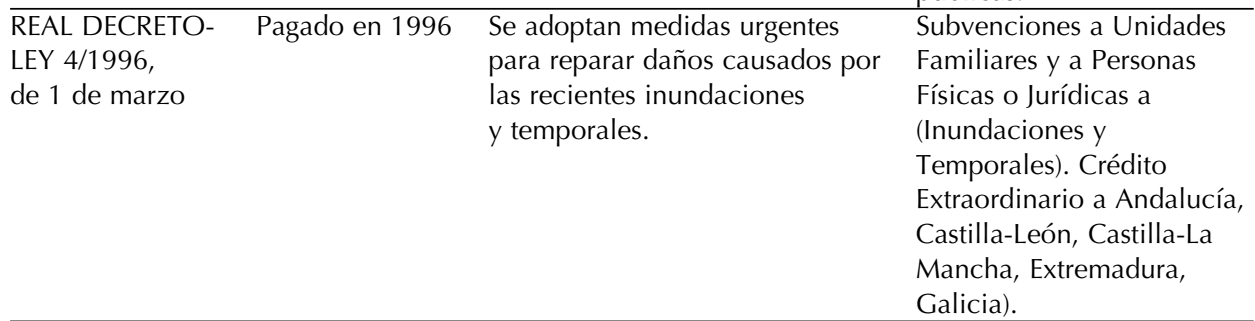


REAL DECRETO-

LEY 13/1996, de

20 de septiembre
Pagado en 1996

para reparar daños causados

la reciente inundación en

Biescas (Huesca).
ORDEN

18-03-1993
Que regula procedimiento para

la concesión de ayudas en atención a determinadas necesidades derivadas de situaciones de emergencia, catástrofes y calamidades públicas a unidades familiares.
Subvenciones a Unidades

Familiares y a Personas

Físicas o Jurídicas a

Huesca (Biescas) (lluvias

fuertes e inundaciones).

Subvenciones a Unidades

Familiares y a Personas

Físicas o Jurídicas a Álava,

Almería, Badajoz,

Barcelona, Cádiz,

Cantabria, Castellón,

Ciudad Real, Córdoba,

Granada, Guipúzcoa,

Huelva, Huesca, Jaén,

La Coruña, Lugo, Madrid,

Málaga, Orense, Palencia,

Salamanca, Segovia,

Sevilla, Valencia, Vizcaya,

Zaragoza, Zamora.

\begin{tabular}{lll}
\hline REAL DECRETO- & Pagado en 1997 & Se adoptan medidas urgentes \\
LEY 4/1996, & & para reparar daños causados por \\
de 1 de marzo & & las recientes inundaciones \\
& y temporales.
\end{tabular}

Subvenciones a Unidades

Familiares y a Personas

Físicas o Jurídicas

a La Coruña, Ávila, Madrid, Cádiz, Zamora, Córdoba, Jaén, León, Sevilla, Málaga, Huelva, Soria (temporales de lluvias y vientos).

\begin{tabular}{lll}
\hline REAL DECRETO- & Pagado en 1997 & Se adoptan medidas urgentes \\
LEY 13/1996, & para reparar daños causados por \\
de 20 de septiembre & la reciente inundación en \\
& Biescas (Huesca).
\end{tabular}

\begin{tabular}{lll}
\hline REAL DECRETO- & Pagado en 1997 & Se adoptan medidas urgentes \\
LEY 2/1997, & & para reparar daños causados por \\
de 14 de febrero & inundaciones y temporales de
\end{tabular}
inundaciones y temporales de Jísicas o Jurídicas de nieve acaecidos en la Comunidad Cantabria.

Autónoma de Cantabria.

REAL DECRETO- $\quad$ Pagado en 1997 Se adoptan medidas urgentes para $\quad$ Subvenciones a Unidades LEY 4/1997, reparar daños causados por temporales de lluvia y nieve desde el mes de agosto del Familiares y a Personas de 14 de marzo pasado 1996 y hasta los primeros meses del presente año.

Subvenciones a Unidades

Familiares y a Personas

Físicas o Jurídicas a Huesca (Biescas) (lluvias fuertes e inundaciones). Subvenciones a Unidades Familiares y a Personas Físicas o Jurídicas de

Físicas o Jurídicas a Andalucía, CastillaLa Mancha, Asturias (lluvias fuertes, inundaciones, vientos huracanados), Extremadura y Comunidad Valenciana.

REAL DECRETO- $\quad$ Pagado en 1997 Se adoptan medidas urgentes para Subvenciones a Unidades LEY $11 / 1997$

$\begin{array}{ll}\text { reparar daños causados por } & \text { Familiares y a Personas }\end{array}$ inundaciones en Guipúzcoa.
Físicas o Jurídicas a Guipúzcoa (lluvias de verano y tormentas). 
ORDEN

18-03-1993, de 30 de marzo
Pagado en 1998

Que regula procedimiento para la concesión de ayudas en atención a determinadas necesidades derivadas de situaciones de emergencia, catástrofes y calamidades públicas como Transferencias Corrientes a Corporaciones Locales y a personas físicas o jurídicas.
Subvenciones a

Corporaciones Locales por gastos de emergencia o suministro de agua potable. Requerimientos a empresas privadas para realizar una prestación personal o de bienes en materia de protección civil.

Subvenciones a familias por daños en vivienda, no estructurales y daños en enseres.

Subvenciones a Unidades Familiares y a Personas Físicas o Jurídicas a Lugo, Valencia, Zamora.

\begin{tabular}{lll}
\hline REAL DECRETO- & Pagado en 1998 & Se adoptan medidas urgentes para \\
LEY 18/1997, & reparar daños causados por las \\
de 31 de octubre & fuertes tormentas de granizo \\
& y lluvia acaecidas recientemente \\
& en algunas provincias de distintas \\
& Comunidades Autónomas.
\end{tabular}

Andalucía, Aragón, Asturias, Cantabria, Castilla-

La Mancha, Castilla y León, Cataluña, Extremadura, Comunidad Valenciana, Galicia, La Rioja, Murcia, País Vasco.

\begin{tabular}{lll}
\hline REAL DECRETO- & Pagado en 1998 & Se adoptan medidas urgentes para \\
LEY 24/1997, & reparar daños causados por \\
de 12 de diciembre & inundaciones y temporales de \\
& vientos acaecidos el 5 y 6 \\
& de noviembre de 1997.
\end{tabular}

\begin{tabular}{|c|c|c|}
\hline $\begin{array}{l}\text { REAL DECRETO- } \quad \text { Pagado en } 1998 \\
\text { LEY 29/1997, } \\
\text { de } 19 \text { de diciembre }\end{array}$ & $\begin{array}{l}\text { Se adoptan medidas urgentes para } \\
\text { reparar daños causados por } \\
\text { inundaciones y temporales } \\
\text { de lluvias. }\end{array}$ & $\begin{array}{l}\text { Andalucía, Castilla- } \\
\text { La Mancha, Comunidad } \\
\text { Valenciana y Región de } \\
\text { Murcia. }\end{array}$ \\
\hline $\begin{array}{l}\text { REAL DECRETO- } \\
\text { LEY } 2 / 1998, \\
\text { de } 17 \text { de abril }\end{array}$ & $\begin{array}{l}\text { Se adoptan medidas urgentes para } \\
\text { reparar daños causados por } \\
\text { inundaciones y temporales }\end{array}$ & $\begin{array}{l}\text { Andalucía, Aragón, Castilla- } \\
\text { La Mancha, Castilla y León } \\
\text { y Cataluña. }\end{array}$ \\
\hline
\end{tabular}
acaecidos entre noviembre 1997 y febrero 1998.

ORDEN Pagado en 1999 Que regula procedimiento para la Subvenciones a

18-03-1993, de 30 de marzo concesión de ayudas en atención a determinadas necesidades derivadas de situaciones de emergencia, catástrofes y calamidades públicas como transferencias corrientes a corporaciones locales, a personas físicas o jurídicas y a familias.
Extremadura (Cáceres y Badajoz) y Huelva. corporaciones locales por gastos de emergencia o suministro de agua potable. Requerimientos a empresas privadas para realizar una prestación personal o de bienes en materia de protección civil.

Subvenciones a familias estructurales y daños en enseres.

Extremadura (Cáceres y Badajoz) y Huelva. por daños en vivienda, no
Se adoptan medidas urgentes para reparar daños causados por inundaciones y temporales de vientos acaecidos el 5 y 6 de noviembre de 1997. 
REAL DECRETO- Pagado en 1999 LEY 29/1997, de 19 de diciembre
Se adoptan medidas urgentes para reparar daños causados por inundaciones y temporales de lluvias.

REAL DECRETO-
LEY 2/1998,

de 17 de abril reparar daños causados por inundaciones y temporales
Se adoptan medidas urgentes para acaecidos entre noviembre 1997 y febrero 1998.

REAL DECRETO-
LEY 9/1999

reparar daños causados por los
Andalucía, Castilla-

La Mancha, Comunidad

Valenciana y Región de Murcia.

Andalucía, Aragón,

Castilla-La Mancha,

Castilla y León

y Cataluña.

Se adoptan medidas urgentes para En la Región de Murcia.

movimientos sísmicos acaecidos

durante el mes de febrero de 1999.

\section{ORDEN}

18-03-1993, de 30 de marzo

Pagado en 1999

Que regula procedimiento para la su

Que regula procedimiento para la
concesión de ayudas en atención

a determinadas necesidades

derivadas de situaciones de

emergencia, catástrofes y

calamidades públicas, como transferencias de capital a familias.

\begin{tabular}{ll}
\hline ORDEN & 30-3-93, \\
18-03-1993, & pagado en 2000 \\
de 30 de marzo &
\end{tabular}

de 30 de marzo
Que regula procedimiento para la

concesión de ayudas en atención

a determinadas necesidades

derivadas de situaciones

de emergencia, catástrofes

y calamidades públicas como

transferencias corrientes a

corporaciones locales y a familias.

Subvenciones a unidades familiares y a personas físicas o jurídicas a Lugo, Valencia, Zamora.

El Ejido (Almería).

Subvenciones a familias por daños en vivienda, no estructurales y daños en enseres.

Málaga.

Obras de inestabilidad terrenos Medina Sidonia.

Obras de emergencia

Orihuela del Tremedal

(Teruel).

Consolidación de terrenos

Castropol (Asturias).

Subvenciones a unidades familiares.

\begin{tabular}{llll}
\hline REAL DECRETO- & Pagado en 2000 & $\begin{array}{l}\text { Se adoptan medidas urgentes para } \\
\text { reparar daños causados por }\end{array}$ & $\begin{array}{l}\text { Extremadura (por vientos } \\
\text { e inundaciones). }\end{array}$
\end{tabular}
inundaciones y temporales de vientos acaecidos el 5 y 6 de noviembre de 1997.

\begin{tabular}{lll}
\hline REAL DECRETO- & Pagado en 2000 & $\begin{array}{l}\text { Se adoptan medidas urgentes para } \\
\text { LEY 9/1999, }\end{array}$ \\
de 27 de mayo & & movimientos císmicos acaecidos \\
& durante el mes de febrero de 1999.
\end{tabular}

\section{ORDEN \\ 18-03-1993,} de 30 de marzo

Pagado en 2001

Que regula procedimiento para la concesión de ayudas en atención a determinadas necesidades derivadas de situaciones de emergencia, catástrofes y calamidades públicas como transferencias corrientes a corporaciones locales y subvenciones a unidades familiares.
El Ejido (Almería).

Subvenciones a familias por daños en vivienda, no estructurales y daños en enseres.

Consolidación de terrenos Castropol (Asturias). 
REAL DECRETO- $\quad$ Pagado en 2002

LEY $2 / 2002$,

de 5 de abril
Se adoptan medidas urgentes para reparar daños causados por las Iluvias torrenciales acaecidas el 31 de marzo de 2002. en Santa Cruz de Tenerife y en San Cristóbal de la Laguna (Isla de Tenerife).

Recibido 29.01.08

Aceptado 28.10.08

\section{BIBLIOGRAFÍA}

Ayala-Carcedo, F. J. (2002): "El sofisma de la imprevisibilidad de las inundaciones y la responsabilidad social de los expertos. Un análisis del caso español y sus alternativas", Boletín de la A.G.E., n 33, pp. 79-92.

Ayala-Carcedo, F. J. (2002): "La inundación torrencial del camping Las Nieves (Bisecas, Pirineos) del 7 de agosto de 1996", en Ayala-Carcedo, F. J. y Olcina, J. (eds.), Riesgos Naturales. Una perspectiva global, Ariel, Barcelona.

Ayala-Carcedo, F. J.; Olcina, J. y Vilaplana, J. M. (2004): "Impacto social y económico", Foro Euromediterráneo: Jornada Técnica sobre Aspectos Jurídicos, Económicos y Sociales de las Catástrofes, Dirección General de Protección Civil y Emergencias-Ministerio del Interior, Madrid, $13 \mathrm{pp}$.

Benito, G. et al. (1998): "The geomorphic and hydrologic impacts of the catastrophic failure of flood-control-dams during the 1996 Biescas flood (Central Pyrenees, Spain)", Z. Geomorph., 42, pp. 417-437.

Calvo García-Tornel, F. (2001): Sociedades y territorios en riesgo, Ediciones del Serbal, colección La Estrella Polar, Barcelona, 203 pp.

Camarasa Belmonte, A. M. y Mateu Bellés, J. F. (2000): "Las inundaciones en España en los últimos veinte años: Una perspectiva geográfica", Serie geográfica, n 9, pp. 11-16

Chaline, C. y Dubois-Maury, J. (1994): La ville et ses dangers, Ed. Masson, París, 244 pp.

Cutter, S. L. (1993): Living with Risk, Arnold, Londres-Nueva York, 214 pp.

Cutter, S. L. (1996): "Social Responses to Environmental Hazards", International Social Science Journal, 47(4), pp. 525-536 [reimpreso desde MABOGUNJE, A. (1997): State of the Earth: Contemporary Geographic Perspectives, Blackwell, Oxford, pp. 173-198].

Cutter, S. L. y Solecki, W. D. (1989): "The national pattern of airbone toxic releases", The professional Geographer, 41(2), pp. 149-161.

Dauphiné, A. (2003): Risques et catastrophes. Observer, spatialiser, comprendre, gérer, Armand Colin, París, 280 pp.

Font Tullot, I. (1983): "Algunas observaciones sobre las lluvias excepcionales en la vertiente mediterránea española", Estudios Geográficos, CSIC, Instituto Juan Sebastián Elcano, XLIV, $n^{\circ} 170-171$, pp. 55-60.

García-Ruiz, J. M.; White, S. et al. (2004): "La avenida del barranco de Arás y los riesgos hidrológicos en el Pirineo central español", en Peña, J. L.; Longares, L. A. y Sánchez, M. (eds.), Geografía física de Aragón. Aspectos generales y temáticos, Universidad de Zaragoza e Institución Fernando el Católico, Zaragoza.

Olcina Cantos, J. (1994): Riesgos Climáticos en la Península Ibérica, Penthalon, Madrid, 440 pp.

Olcina Cantos, J. (2006): ¿Riesgos Naturales? I: Sequías e Inundaciones, Editorial Davinci, 219 pp.

Pulido Mañes, T. (1979): El barrio de San Andrés en Santa Cruz de Tenerife, Aula de Cultura, Cabildo Insular de Tenerife, La Laguna- Tenerife, 222 pp. 
Ribas, A.; Ribera, LL. y Saurí, D. (2001): "Flood mapping in Catalonia: a preliminary analysis of vulnerability for the city of Girona", comunicación presentada en el Colloque International Risques et Territoires, Lyon (Francia), del 16 al 18 de mayo de 2001, publicada a les Actes del Congrés, vol. 1, pp.129-140.

Ribas, A.; Roset, D. y Pujadas, M. (1996): "Planeamiento urbanístico y zonación de espacios inundables. Una aplicación a la ciudad de Girona", Ciudad y Territorio, Estudios Territoriales, 106, pp. 841-860.

Ribas, A. y Saurí, D. (coords.) (1997): "Ciutat i riu: I'aigua en I'organització de l'espai rbà", Documents d'Anàlisi Geogràfica, 31, pp. 17-127.

Saurí, D.; Roset, D.; Ribas, A. y Pujol, P. (2001): "The 'escalator effect in flood policy: the case of the Costa Brava, Catalonia, Spain", Applied Geography, 21, pp. 127-143.

Timmerman, P. (1981): "Vulnerability, Resilience and the Collapse of Society", Environmental Monograph 1, Institute for Environmental Studies, Toronto.

Ventura, M.; Ribas, A. y Saurí, D. (2000): "Gestión del agua y conflictividad social en la cuenca del río Muga (Alt Empordà)", Geographicalia, 38, Universidad de Zaragoza, pp. 59-75.

\title{
Resumen
}

El riesgo de lluvias torrenciales-inundaciones es el más perjudicial en España por las consecuencias que ha dejado históricamente. Algunos ejemplos lo corroboran, como la tragedia en Biescas en el año 1996 o la ocurrida en la ciudad de Santa Cruz de Tenerife en 2002. La vulnerabilidad ante este riesgo, en los espacios urbanos y turísticos, sigue siendo muy elevada a pesar de existir medidas de prevención derivadas del sistema de Protección Civil. En el presente artículo se pretende analizar, a través de casos concretos, por qué se vuelven a repetir accidentes con pérdidas muy cuantiosas en vidas humanas y enseres materiales por este riesgo, sobre todo en áreas urbanas, donde, en algunas ocasiones, determinados elementos contribuyen a reforzar las consecuencias negativas de las inundaciones.

Palabras clave: inundaciones; vulnerabilidad; riesgos; espacios urbanos.

\begin{abstract}
Torrential rains-floods hazard is the most damaging in Spain considering historic consequences. There are some supporting examples; i.e. the tragedy in Biescas (Huesca) in 1996 or the one in Santa Cruz de Tenerife in 2002. There are contingency plans derived from the emergency system of Protección Civil (Civil Defence), but this support does not avoid the high vulnerability of urban and tourist localities. This article analyzes, through specific examples, why this hazard continuously causes accidents/damages with substantial losses in humans and goods specially in urban localities where sometimes, some elements contribute to reinforce to the negative consequences of floods.
\end{abstract}

Key words: flash-flood; vulnerability; hazards; urban localities. 